\title{
Experimental Assessment of a Modal-based Multi-parameter Method for Locating Damage in Composite Laminates
}

\author{
D. Montalvão ${ }^{\mathrm{a}, \mathrm{b},{ }^{*}}$, A.M.R. Ribeiro ${ }^{\mathrm{b}}$, J. Duarte-Silva ${ }^{\mathrm{a}}$ \\ ${ }^{a}$ Department of Mechanical Engineering, Escola Superior de Tecnologia, Polytechnic Institute \\ of Setúbal, Campus do IPS, Estefanilha, 2910-761 Setúbal, Portugal \\ ${ }^{b}$ Department of Mechanical Engineering, Instituto Superior Técnico, Technical University of \\ Lisbon, Av. Rovisco Pais, 1049-001 Lisbon, Portugal
}

\begin{abstract}
The low specific weight of composite materials, along with their excellent mechanical properties, makes them suitable to be widely used in many modern engineering structures. However, composite materials are quite sensitive to impacts: a specific kind of damage, called Barely Visible Impact Damage (BVID), may occur, constituting an unsafe failure of difficult assessment. In the past years several methods have been developed with the aim of assessing this type of damage. In this paper, a vibration-based technique that combines both the natural frequencies and the modal damping factors as damage sensitive features is tested for locating impact damage in carbon fibre reinforced laminates.

The method is intended to be used for locating damage in real laminated composite structures that undergo in-service impacts, such as an airplane's fuselage or wings. A minimum of one response coordinate is the strict requirement during each inspection, because it uses the dynamic global parameters of the structure as damage features. This is possible because the method assumes that, at least for BVID, the mode shapes remain practically unchanged.

The theory is summarized and the method is tested with experimental examples where damage is introduced at different locations. Additionally, the hypothesis that different damage morphologies on composite materials have different contributions to the damage features is addressed.
\end{abstract}

Keywords: Structural Health Monitoring; Damage; Delamination; Composites; Vibration.

\footnotetext{
* Corresponding author. Tel.: +351 265790 000; fax: +351 265721869.
}

E-mail addresses: diogo.montalvao@estsetubal.ips.pt (D. Montalvão), aribeiro@dem.ist.utl.pt (A.M.R. Ribeiro), duarte.silva@estsetubal.ips.pt (J. Duarte-Silva). 


\section{Introduction}

The low specific weight of composite materials, along with their excellent mechanical properties, makes them suitable to be used in many modern engineering structures: from the BMW Oracle sailboat, winner of the $33^{\text {rd }}$ America's Cup, to aircrafts such as the Airbus A380 or the Boeing 787 Dreamliner, they can be seen in a wide variety of applications.

However, composite materials are very sensitive to impact loads. In aeronautical structures, the components may be subjected to low energy impacts caused by dropped tools or mishandling during assembly and maintenance; low to medium energy impacts caused inservice by foreign objects such as hailstones, stones or birds; and high energy impacts caused by weaponry projectiles in military planes $[1,2,3]$.

The failure modes of laminate composite materials are very different from those found in more conventional engineering materials, such as metals. Typical failure modes in laminated composite materials may be found, for instance, in [3, 4]. In a high energy impact (for instance, from a bullet), the damaged area is generally small but penetration is total (thus visible). In a medium energy impact, it is usually possible to visually detect the damage location, which is characterized by a pronounced local indentation. In a low energy impact (but high enough to produce damage), only a slight indentation will be seen on the impact surface (figure 1, to the left). This level of damage is often referred to as Barely Visible Impact Damage (BVID). Generally, Carbon Fibre Reinforced Polymers (CFRPs) are very sensitive to medium and low energy impacts. Impact damage is introduced only if the impact force reaches a certain threshold level. After the impact, matrix cracks may propagate and interact among themselves reaching the interfaces between plies. High transverse shear stresses will grow and delamination - the debonding between two adjacent plies - appears. On the opposite side of the impact, fibre breakage may occur as a consequence of the development of high tensile forces due to bending (figure 1, to the right). In such cases, very severe structural damage may occur in an aircraft shell although the impact may hardly be perceived on the outer surface, where the impact happened. 

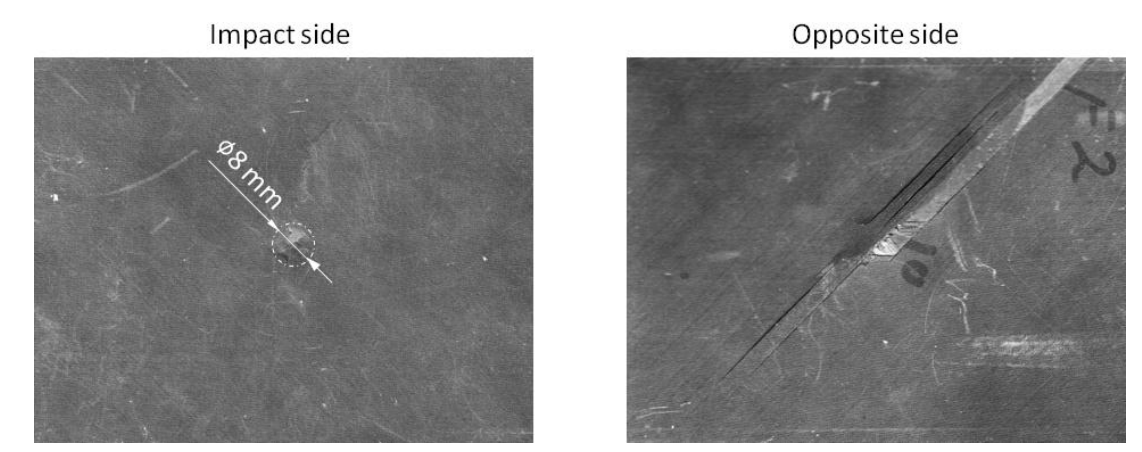

Fig. 1: Example of the external aspect on each side of a laminate with BVID.

This matter has received some attention for damage analysis; for example, in [5] a study is presented on the influence of the laminate thickness on the resistance to repeated low energy impacts on glass, carbon and aramid fabrics reinforced composites, for different levels of impact energy. Studies addressing multiple impact test methods and numerical modelling developments on metallic, concrete, and composite structures are discussed in [6].

The main idea behind damage detection techniques based on structural dynamic changes is the fact that the modal parameters (natural frequencies, mode shapes and modal damping) are functions of the physical parameters (mass, stiffness and damping) and thus it is reasonable to assume that the existence of damage leads to changes in the modal properties of the structure.

Most of the traditional vibration-based methods for damage assessment are based on the fact that damage leads to appreciable reduction in the stiffness of a structural element. Interlaminar delamination may be seen as a reduction in the part stiffness and buckling load. For instance, in [7], it is shown that the contact forces between delaminated layers, the delamination extension and the delamination location have an influence on the resonant frequencies.

Nevertheless, in structures made of composite materials and to which delamination is concerned, there seems to be a tendency to consider damping as a rather sensitive feature to damage. In [8] it was observed that the energy dissipation in a Carbon Fibre Reinforced Polymer (CFRP) is mostly induced by the interfacial slip across the delamination and the tendency for mutual penetration between the surfaces in the delamination region. In such a case, the material is locally heterogeneous and damping may be expected to increase [9], dependent on the deformation shape. Thus, it is reasonable to assume that the modal damping factors, which are associated with the dissipated energy, may be used in Structural 
Health Monitoring (SHM) techniques. In fact, other authors have also suggested damping to be used as a feature in damage detection techniques $[10,11,12]$.

Nevertheless, for thin laminates and in real situations, fibre breakage is very likely to occur because of the bending stresses in the back side of the laminate. If one imagines that each fibre acts as a spring-damper and that the breakage corresponds to the interruption of the spring-damper connection, it is reasonable to assume that a local change in both stiffness and damping may happen. Furthermore, the debonding between two adjacent laminae will reduce the bending stiffness.

Based on another paper [13], an inverse modal-based technique for locating damage that combines both the natural frequencies and the modal damping factors as damage sensitive features is tested here. Each feature's relative sensitivity to damage is estimated by resorting to weighting coefficients that depend on the dispersion of their variation.

The method is assessed with experimental examples where damage is inflicted at different locations. In some cases, the damage severity is increased with the purpose of understanding how the damage features react. It will be shown that there is consistency in the way the damage features are affected when damage locally increases.

Composite laminates are used mainly for plates, shells and like parts. Without loss of generalization and for simplicity sake, the following formulation and example assume a bidimensional part.

\section{Theoretical background}

\subsection{The Damping Damage Indicator (DaDI)}

In the presence of a delamination, it is reasonable to assume that frictional forces will develop between the bottom and top surfaces of the adjacent layers when bending motion is imposed as a consequence of shear loads. Thus, consider that a delamination in a composite laminate leads to increased values in the modal damping factors, $\eta_{r}(r=m$.. $n$ where $m$ and $n$ are the first and last modes respectively in the measured frequency range). The relative difference between the undamaged and damaged states of the modal damping values for mode $r$ may be expressed by:

$$
\Delta \eta_{r}^{D}=\frac{\left|\eta_{r}^{D}-\eta_{r}\right|}{\eta_{r}} \times 100 \%
$$


where the superscript ${ }^{D}$ stands for damage. These relative differences are obtained independently of the coordinates under consideration, as they are based on global properties of the structure. However, in the case that a discrepancy exists due to localized damage, this means that some kind of function must be used to relate this global variation to the local coordinates of the structure. This is accomplished by assuming that different mode shapes have different sensitivities depending on the locations where delamination damage is present. Thus, a generalized Plane Shape Function (PSF) is defined for mode $r$ at each point $(i, j)$ of the part as a function of the mode shape. The strain energy might be a promising candidate for building a PSF, since the hysteretic damping assumes the loss by friction of a fraction of the strain energy. For a state of plane-stress, the strain energy density is:

$$
U_{0}=\frac{1}{2}\left(\sigma_{x x} \varepsilon_{x x}+\sigma_{y y} \varepsilon_{y y}+\sigma_{x y} \varepsilon_{x y}\right)
$$

The distortion in the $x y$ plane influence on the damping factor variation due to delamination damage is considered of no relevance (in practice, experiments showed it tended to diminish the accuracy of the method). Therefore, only the part relating extensional stresses and strains is considered. Thus, the definition of a PSF when damping changes are concerned in bidimensional structures is proposed as follows:

$$
{ }_{\eta_{r}} P S F_{i j}={ }_{r} \sigma_{x x_{i j}} \cdot{ }_{r} \varepsilon_{x x_{i j}}+{ }_{r} \sigma_{y y_{i j}} \cdot{ }_{r} \varepsilon_{y y_{i j}}
$$

Finally, it is assumed that the mode shapes and the natural frequencies will not suffer a considerable change when comparing the undamaged and damaged states of the structure ${ }^{1}$. Consequently, the PSF will also remain essentially unchanged. Then, an index, called Damping Damage Indicator ( $\mathrm{DaDI})$, is proposed as:

$$
\operatorname{DaDI}_{i j}=\frac{\sum_{r=\mathrm{m}}^{n}\left(\eta_{r} P S F_{i j} \cdot \Delta \eta_{r}^{D}\right)}{\sum_{r=\mathrm{m} \eta_{r}}^{n} P S F_{i j}}
$$

\subsection{The Frequency Damage Indicator (FreDI)}

\footnotetext{
${ }^{1}$ Later, it will be shown that damage introduces only slight variations in the mode shapes.
} 
Consider that damage, regardless of any change in damping, leads to changes in the stiffness, i.e., in the natural frequencies $\omega_{r}$, due to fibre breakage. The relative difference between the undamaged and damaged state of the natural frequency of mode $r$ is expressed by:

$$
\Delta \omega_{r}^{D}=\frac{\left|\omega_{r}^{D}-\omega_{r}\right|}{\omega_{r}} \times 100 \%
$$

As for the hysteretic damping, the relative difference of the natural frequencies between the healthy and damaged states is obtained independently of the coordinates, since it is based on a global property of the structure. Thus, some sort of arbitrary function with mode dependent physical quantities may also be used to locate damage. For a given load the strain is a measure of the flexibility of the structure, so it can be used as a PSF for a damage index based on the changes of the resonant frequencies. Hence, when computing such index the following form of the PSF is proposed:

$$
{ }_{\omega_{r}} P S F_{i j}=\left|{ }_{r} \varepsilon_{x x_{i j}}+{ }_{r} \varepsilon_{y y_{i j}}\right|
$$

Then, an index, called Frequency Damage Indicator (FreDI), is proposed as:

$$
F r e D I_{i j}=\frac{\sum_{r=\mathrm{m}}^{n}\left(\omega_{r} P S F_{i j} \cdot \Delta \omega_{r}^{D}\right)}{\sum_{r=\mathrm{m} \omega_{r}}^{n} P S F_{i j}}
$$

\subsection{The Multi-parameter Damage Indicator (MuDI)}

Now it is time to combine the predictions from both the indexes DaDI and FreDI for the damage location:

$$
M u D I_{i j}=W_{f} \cdot \frac{F e D I_{i j}}{\max \left|\left[F r e D I_{i j}\right]\right|}+W_{d} \cdot \frac{D a D I_{i j}}{\max \left|\left[D a D I_{i j}\right]\right|}
$$

in which $W_{f}$ is a weighting function affecting the frequency term and $W_{d}$ is a weighting function affecting the damping term that will be treated next. This index (8) is called Multiparameter Damage Indicator (MuDI).

It is easier to treat the weighting functions as if they are on the opposite sides of a scale:

$$
W_{f}+W_{d}=1
$$


The weighting functions' values are based on the dispersion of the variation of the modal frequencies and modal damping factors. The relative standard deviations $\sigma_{\Delta \eta}$ and $\sigma_{\Delta \omega}$ for the set of values $\Delta \eta_{r}^{D}$ and $\Delta \omega_{r}^{D}$ respectively are determined. Then, the frequency weighting function is defined as:

$$
W_{f=} \frac{\kappa \cdot \sigma_{\Delta \omega}}{\sigma_{\Delta \eta}+\kappa \cdot \sigma_{\Delta \omega}}
$$

in which $\kappa$ is a scale factor:

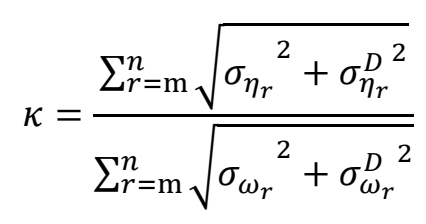

where $\sigma_{\omega_{r}}$ and $\sigma_{\eta_{r}}$ are the relative standard deviations of each mode's natural frequencies $\omega_{r}$ and modal damping factors $\eta_{r}$ obtained after the modal identification process.

So, by imposing equation (9), the damping weighting function $W_{d}$ can also be calculated.

\section{Procedural guidelines and experimental setup}

\subsection{Test setups for damage assessment}

For the experimental assessment of the performance of the proposed indexes, CFRP quasiisotropic plate specimens with approximate dimensions $392 \times 242 \times 2.1 \mathrm{~mm}$ were tested. These specimens are made from a [0/45/-45/90]s layup of woven prepreg constituted by Hexcel ${ }^{\circledR}$ G803 3K $5 \mathrm{H}$ satin carbon fibre impregnated in HexPly ${ }^{\circledR} 200$ phenolique matrix (200/40\%/G803). These laminates are used in some parts of military aircrafts, such as the Lockheed Martin C-130 airplane.

The specimen plates were tested in a free-free configuration, suspended by two nylon strings set $50 \mathrm{~mm}$ away from the top corners.

A PULSE ${ }^{\mathrm{TM}}$ system from Brüel \& Kjær ${ }^{\circledast}$, including a signal acquisition module (Brüel \& $\mathrm{Kjær}^{\circledast}$ type 3109) and LAN interface module (Brüel \& $\mathrm{Kjær}^{\circledast}$ type 7533), was used for both the signal generation and acquisition. 
Experimental testing was carried out in the $0-800 \mathrm{~Hz}$ frequency range ${ }^{2}$ with multi-sine excitation signals introduced by means of a stinger attached to an electromagnetic shaker (Brüel \& $\mathrm{Kjær}^{\circledR}$ type 4809). Four points, with coordinates ${ }^{3}$ shown in figure 2, were used to measure the velocity response using a Dual-channel LDV from Polytec ${ }^{\circledR}$ (interferometer OFV508 and controller OFV-2802i) and target reflective tape 3M Scotchlite ${ }^{\mathrm{TM}}$. The force was measured with a force transducer (Brüel \& $\mathrm{Kjær}^{\circledR}$ type 8200) connected to a charge amplifier (Brüel \& Kjær $^{\circledast}$ type 2706) and fastened to the top left corner of the plate.

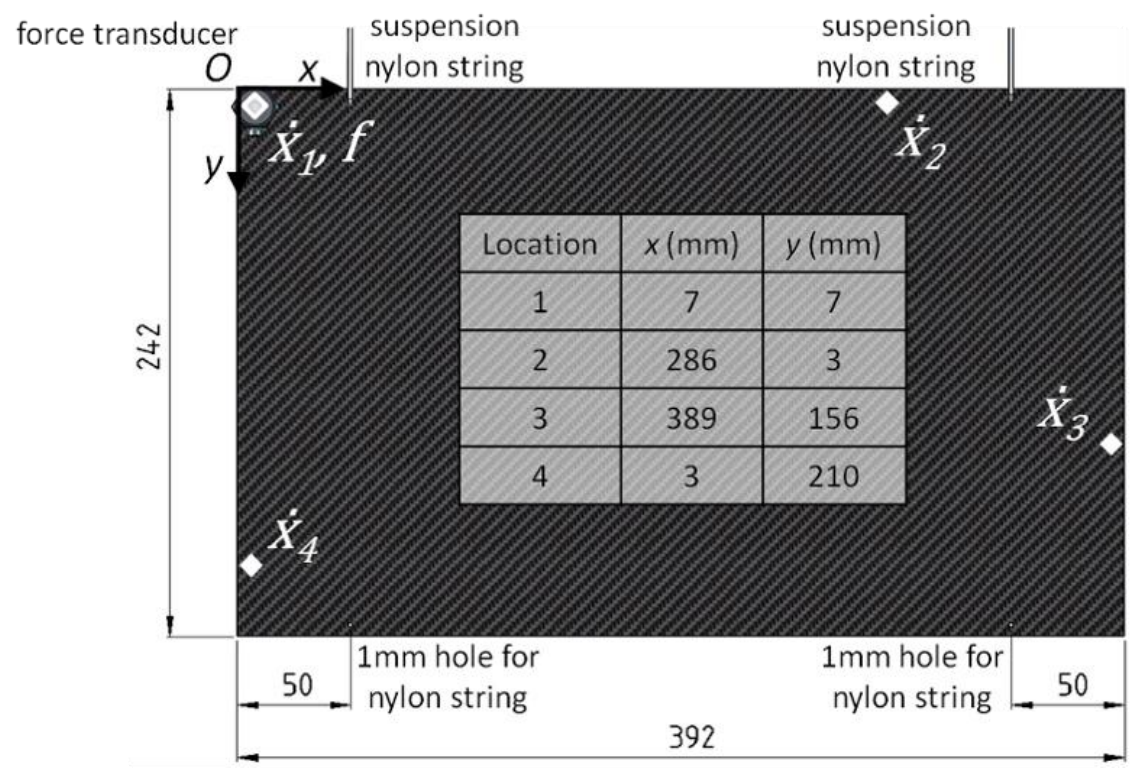

Fig. 2: Specimen plate type ' $A$ ', with force excitation point and response measurement locations.

\subsection{Extracting mode shapes}

In order to obtain a spatial description of the mode shapes of the structure, one of the following approaches could be used:

\footnotetext{
${ }^{2}$ Except for the healthy state of plate $\mathrm{A} 1$, later on referred to as $\mathrm{A} 1 \mathrm{H}$, where testing was carried out in the 0 to $400 \mathrm{~Hz}$ frequency range. Soon after, the frequency range was increased in order to get more modes.

${ }^{3}$ Except for the direct FRF, all the other response measurement locations were chosen so that they would not be over a nodal line of the plate up to $400 \mathrm{~Hz}$, as shown later in figure 4 .
} 
- A Scanning LASER Doppler Vibrometer (SLDV), or similar device, is used to measure the responses in several nodes to a single-point excitation. Based on the out-of-plane displacements, the strains can be estimated using numerical methods;

- A FE model of the structure - that can be obtained with ANSYS ${ }^{\circledR} 11$ or similar software, using an analysis of the type Modal - can be used alternatively.

If a FE model is chosen, it is advisable to resort to experimental data, anyway, for validation, which means that both approaches can be used together. With the mode shapes, it is possible to define the PSF in the forms presented earlier since ${ }_{r} P S F_{i j}={ }_{r} P S F_{i j}\left(\psi_{r}(i, j)\right)$ with $\psi_{r}(i, j)$ being the mode shape for the element with geometrical coordinates $(i, j)$.

Remark that an analytical approach was not considered in order to avoid limiting the method to uses where the geometry is simple enough.

For the PSF, the specimen was modelled as an isotropic homogeneous material in ANSYS $^{\circledR} 11$ with a total of $56 \times 35$ (1960) SHELL63 elements (6 DOF per each of the 4 nodes) in a free-free configuration. Several different approaches, from theoretical to experimental, were followed [14] to determine the mechanical properties of the specimens' constituent materials, namely the Young's and shear's moduli, specific weight, Poisson's ratios and damping factors. As far as damping is concerned, the peculiarities of its measurement in composite materials was previously addressed in [15]. Tensile tests showed that the composite layup being studied could in fact be approximated by an isotropic homogeneous material. The following properties were estimated:

- $\mathrm{E}=44.64 \mathrm{GPa}$;

- $\mathrm{v}=0.33$;

- $\rho=1508 \mathrm{~kg} / \mathrm{m}^{3}$;

- $\eta=0.0027$.

The transducers are treated as part of the structure, in order to avoid the use of mass cancelling techniques. Since a non-contact response transducer was available (a LASER vibrometer) only the force transducer must be considered. The used force transducer was a Brüel \& $\mathrm{Kjær}^{\circledR}$ type 8200 with a theoretical active mass of $18 \mathrm{~g}$ (out-of-plane direction), total mass of $21 \mathrm{~g}$ and (estimated) mass moments of inertia $\mathrm{I}_{\mathrm{x}}=\mathrm{I}_{\mathrm{y}}=1.33 \times 10-6 \mathrm{kgm}^{2}$ and $\mathrm{I}_{\mathrm{z}}=8 \times 10^{-7} \mathrm{kgm}^{2}$. The force transducer was modelled as a zero-thickness distributed mass with concentrated mass moments of inertia occupying a closely square area of $2 \times 2$ elements. In spite of the fact 
that its real geometry is circular, the square side is approximately of the same dimension of the diameter of the threaded mount pad. The mass moments of inertia of the force transducer were modelled in a single node with a MASS21 element at the centroid of the $2 \times 2$ square region. At this same point, a spring with $500 \mathrm{~N} / \mathrm{m}$ stiffness, modelled with a COMBIN14 line element, was attached in order to simulate some of the constraint effects introduced by the push-rod.

FE model validation (for computing the PSF function correctly) was carried out with data obtained using Scanning LDVs.

The excitation force was of the sweep-sine type and it was introduced using an electromagnetic shaker (Brüel \& $\mathrm{Kjær}^{\circledR}$ type 4809) and a threaded Teflon stinger. The force was measured with a force transducer (Brüel \& $\mathrm{Kjær}^{\oplus}$ type 8200) and charge amplifier (Brüel \& Kjær $^{\circledR}$ type 2706).

The frequency ranges were from 0 up to $400 \mathrm{~Hz}$ (test 1) and from 0 to $800 \mathrm{~Hz}$ (test 2).

The responses were measured by the direct reflection of the LASER beam from the dark rough surface of the specimen (without using any kind of reflective tape), showing evidence of some noise in certain nodes (still, the results were quite satisfactory). A total of $13 \times 9$ (117) nodes of a square-like element mesh were used for the measurement of the velocity responses. This mesh covered the whole plate's surface.

Test 1 used a different Scanning LDV than test 2: Polytec ${ }^{\circledR}$ controller OFV-3001, junction box PSV-Z-040M and LASER head OFC-056. During test 2 a Polytec ${ }^{\circledR}$ Scanning LDV, composed of a combination of head PSV-400, controller OFV-5000 and junction Box PSV-400, was used for both the signal generation and data acquisition, as shown in figure 3.

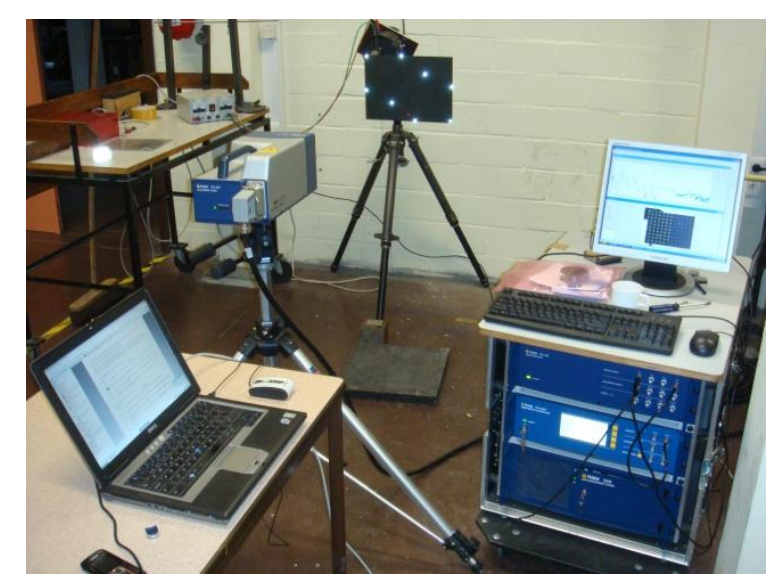


Fig. 3: Illustrating picture of the experimental apparatus (Laboratory of the Acoustics and Vibration Research Group, Faculty of Applied Sciences, Vrije Universiteit Brussel).

For validation (and choice) of the model to be used in the succeeding tasks, test data was compared to the numerical (FE model) results. The data was first observed with the Polytec Scan Viewer 1.31 software and later processed with BETAlab ${ }^{\circledR}$ software for improvement of the results ${ }^{4}$. In fact, it is recognized $[16,17]$ that it is necessary to tune the FE models' parameters - either those that are valid for static (or quasi-static) situations or others difficult to accurately model, such as joints - in order to provide a reliable reproduction of the vibration test results. When performed systematically, this process is known as Updating. In the present case, the model parameters' adjustments were sufficiently small for obtaining the desired correspondence through a manual tuning of some of the material properties, namely the shear modulus.

\subsection{Introducing damage into the specimens}

To decide the locations for the damage that would provide good case studies, the mode shapes in the 0 to $400 \mathrm{~Hz}$ frequency range were superimposed and the coordinates for introduction of damage in specimen plates $A 1$ and $A 2$ were chosen in such a way they would be close to the nodal lines of some modes and the anti-nodal lines of other modes. As a first approach, this seemed to be a reasonable choice for validation of the proposed technique since the algorithm is based on the premise that different modes have different sensitivities to damage. In all the other cases the introduction of damage did not have this in mind and can be seen as random choices. Figure 4 shows the overlap of the modal nodal lines (up to $400 \mathrm{~Hz}$ ), the locations of the damage and of the measurement transducers. Damage locations identified with a mark $\left(A 2^{\prime}, A 5^{\prime}\right)$ are obtained through a $180^{\circ}$ rotation of the plate.

\footnotetext{
${ }^{4}$ Polytec Scan Viewer 1.31 is freeware software for visualization purposes of the mode shapes only. BETAlab ${ }^{\odot}$ is a modal identification program that makes use of the Characteristic Response Function $[18,19]$. This software was fully developed by the first author in LabVIEW ${ }^{\mathrm{TM}}$ 7.1 from National Instruments ${ }^{\mathrm{TM}}$. It is used to find the modal parameters from experimental FRFs.
} 


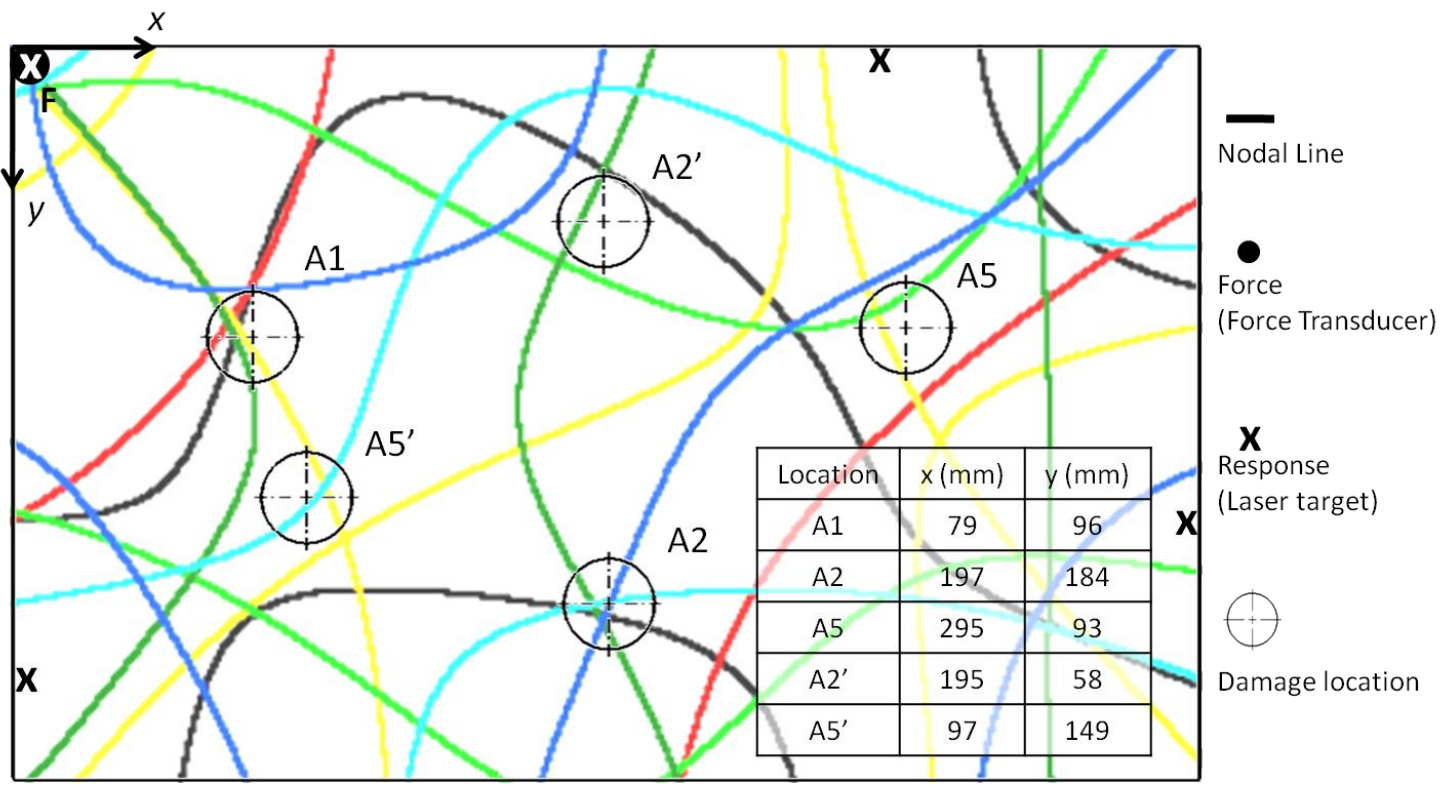

Fig. 4: Experimental damage locations.

Damage was introduced in several different ways, in order to reproduce real life varying damage scenarios. Plates $A 1$ and $A 2$ were at first subjected to one impact in an IMATEK $^{\circledR}$ impact testing machine, turning the plates into damaged states A1D and A2D.

It was the purpose of this work to introduce BVID into the specimens; in other words, the impacts should be "low" to "medium" energy impacts. A $15 \mathrm{~mm}$ diameter hemispheric indentator with a total mass of $2.485 \mathrm{~kg}$ dropped from a $275 \mathrm{~mm}$ and a $225 \mathrm{~mm}$ height for, respectively, plates $A 1$ and $A 2$, would produce the type of damage being looked for. The plates were supported on a $50.8 \mathrm{~mm}$ diameter aluminium cylinder with $12 \mathrm{~mm}$ wall's thickness.

Considering that other authors (for instance, $[4,20]$ ) assessed the similitude of impact results with those obtained from quasi-static loading, damage was introduced into plate A5 by quasistatic loading instead using a press machine. Also, to obtain several degrees of damage for the same specimen, it was necessary to increase the severity of the damage already introduced. This was done using a quasi-static load from the same press machine.

In the case of specimen plates type ' $A$ ', only 4 responses were measured, using a Dual-channel LDV, as it is also represented in figure 4 . The response locations are marked with crosses. Exception made to the direct FRF, all the other responses are measured away from nodal lines (in the 0 to $400 \mathrm{~Hz}$ frequency range) to avoid missing some modes. 


\begin{tabular}{|c|c|c|}
\hline Case & Indentation side & Opposite side \\
\hline A1DD & & \\
\hline A2DD & & \\
\hline$\left(A 2^{\prime} \mathrm{DD}\right)$ & & \\
\hline A5DD & & \\
\hline$\left(A 5^{\prime} \mathrm{DD}\right)$ & & \\
\hline
\end{tabular}

Fig. 5: Snapshots of the final damage case in the loaded specimen plates (the images scales may not be exactly the same from case to case. All the photos were taken from around the same distance of $8 \mathrm{~cm}$ ).

Snapshots of the final damage in the involved specimens are shown in figure 5 . These are thin laminates ( $\cong 2 \mathrm{~mm}$ ) and that is what is believed to be the main reason for damage not being the typical BVID.

On the whole, each one of the three specimens studied, experienced three levels of damage:

- $\quad H$ - No damage cases (healthy states): $A 1 H, A 2 H, A 5 H$ (plus $A 2^{\prime} H, A 5^{\prime} H$ );

- D - Damage cases: A1D, A2D, A5D (plus A2'D, A5'D);

- $\quad$ DD - Increased damage cases: cases A1DD, A2DD, A5DD (plus A2'DD, A5'DD).

The method involves a comparison between two states of the structure: H-D, D-DD or H-DD. Thus, in the end, a total of $3 \times 5=15$ damage cases were studied with 3 specimens only.

\subsection{Extracting dynamic properties}

In order to identify the dynamic properties (modal damping factors and natural frequencies) of both the undamaged and damaged states of the structure, a modal identification technique was performed on the FRFs obtained from EMA. The FRFs were experimentally obtained with the test setups previously described, by testing the same plate before and after damage was introduced. 
In the present case the modal features were identified using BETAlab ${ }^{\odot}$. This application allows analytically regenerating each FRF in the form of the receptance:

$$
\alpha_{j k}(\omega)=\frac{\bar{X}_{J}}{F_{k}}=-\frac{1}{\omega^{2} \bar{M}_{j k}^{R}}+\sum_{r=m}^{n} \frac{{ }^{\bar{A}_{j k}}}{\omega_{r}^{2}-\omega^{2}+i \eta_{r} \omega_{r}^{2}}+\frac{1}{\bar{K}_{j k}^{R}}
$$

where the number of modes was limited between $m$ and $n ; \bar{X}_{J}$ is the complex response amplitude ${ }^{5}$ in coordinate $j ; F_{k}$ is the amplitude of the applied force in coordinate $j ;{ }_{r} \bar{A}_{j k}$ is a complex quantity known as modal constant that depends on the eigenvectors, or mode shapes, $\psi_{r}(i, j) ; \omega_{r}$ is the natural frequency; $\eta_{r}$ is the modal damping loss factor; and $\bar{M}_{j k}^{R}$ and $\bar{K}_{j k}^{R}$ are, respectively, the mass and stiffness complex residuals accounting for the effects of out-of-range modes.

\subsection{Summary of the process}

In the end, the damage indicator is obtained from different types of input data. The output is a probability $^{6}$ map for the location of damage over the full set of coordinates $(x, y)$ that geometrically describe the model. Rather than just a formula, the way the proposed damage index is determined can be better understood as an algorithm. The whole sequential process is illustrated as a fluxogram-like scheme in figure 6 , in which all the inputs for the damage index are represented.

\footnotetext{
${ }^{5}$ Often called phasor, this quantity is complex because it includes the phase. In the case of the formula shown, it is a displacement, but it could be a velocity or acceleration instead.

${ }^{6}$ Sometimes the term "probability" will be used in the course of this text when referring to the damage location index. It would be more correct to use terms such as "likelihood" instead, as "probability" is not used in a strict mathematical sense. However, we thought the word "probability" would be quite suggestive.
} 


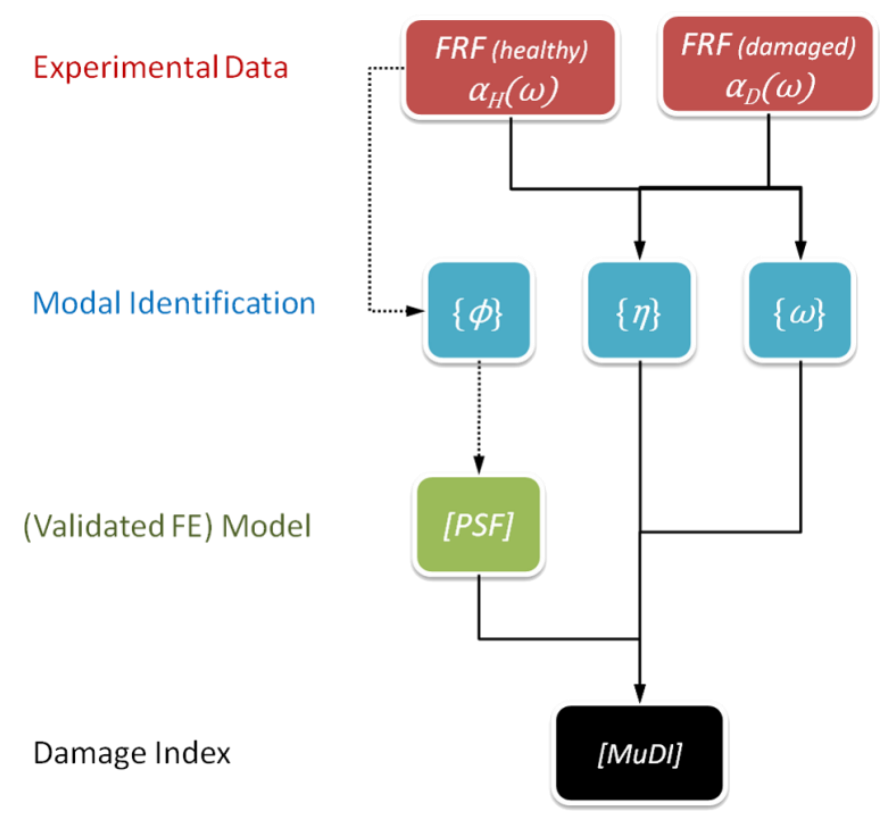

Fig. 6: Schematic representation of the algorithm sequential stack (steps illustrated with broken lines are only possible if validation of a FE model is feasible).

The implementation of the whole procedure requires a lot of information to be processed; so, a program called $\mathrm{MuDI}^{\mathrm{O7}}$ was developed with the aim of helping to perform the tasks shown in figure 6 .

\section{Results}

\subsection{Validation of the initial assumptions}

The first approach was to compare results obtained from a "prototype" plate called A0 before and after introducing damage. This plate was the very first to be manufactured for this research work as a way for practicing and finding problems related to the manufacturing process of the specimens. Visible damage was afterwards introduced successively with quasistatic loading. The dynamic tests were done using 8 modes in the 0 to $400 \mathrm{~Hz}$ frequency range. BETAlab $^{\odot}$ was used for the modal parameter identification. Results are shown in figure 7. The major conclusions to be drawn from appreciation of these pictures are the following:

\footnotetext{
${ }^{7} \mathrm{MuDI}^{\odot}$ is a custom made program which allows the implementation of the damage location algorithm proposed in this work. It was fully developed by the authors in LabVIEW 7.1 from National Instruments ${ }^{\mathrm{TM}}$.
} 
- The damage introduces slight shifts in the modal frequencies, for which the largest variation observed was around $2 \%$ only;

- The modal damping factors suffered important changes, showing variations over $30 \%$ for some modes (in this particular case, the $3^{\text {rd }}, 4^{\text {th }}$ and $8^{\text {th }}$ ).
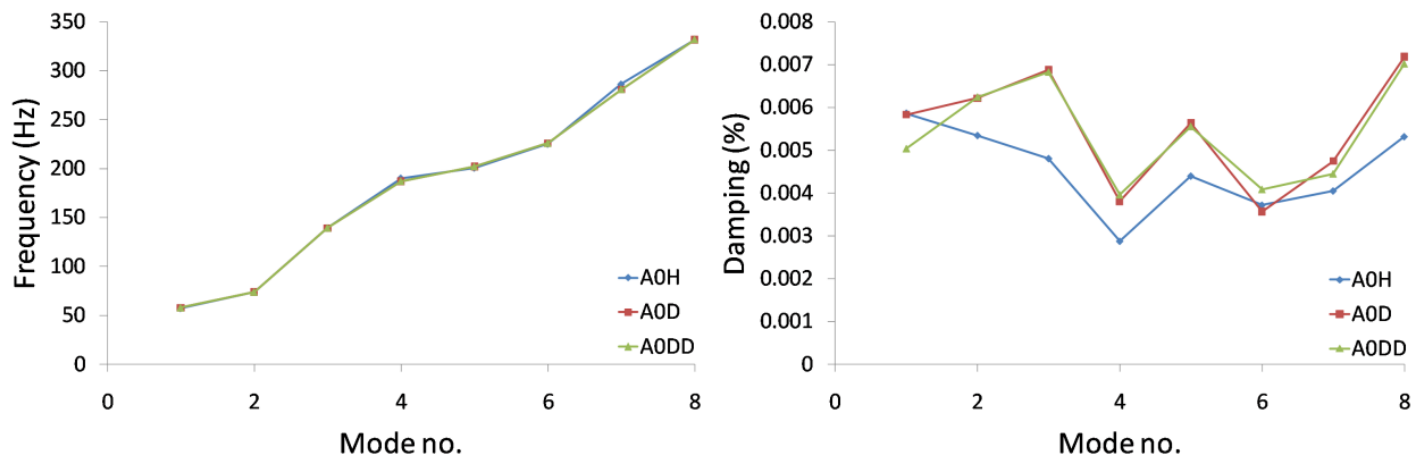

Fig. 7: Frequency and damping between cases $A O H, A O D$ and $A O D D$.

For the other plates, a comparison was established between the undamaged and damaged states in order to understand if the mode shapes would present significant changes as a consequence of damage. It was observed that damage only introduces very slight variations that can hardly be noticed. Some illustrating results are shown in figure 8 , for the case $\mathrm{A} 1 \mathrm{H}$ A1D. 


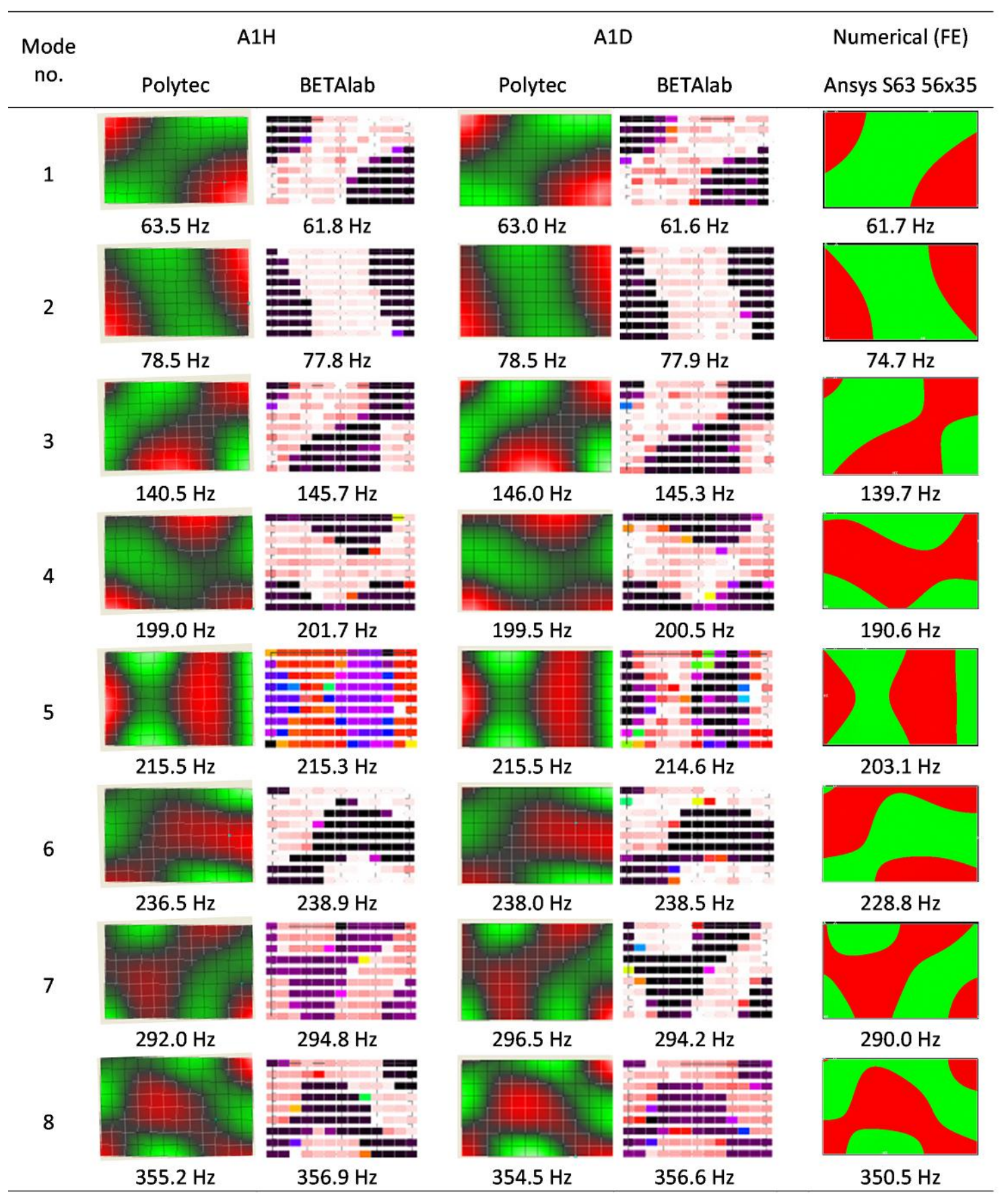

Fig. 8: Comparison between experimental (Polytec), regenerated from identified parameters $\left(\right.$ BETAlab $^{\odot}$ ) and numerical (ANSYS ${ }^{\circledR} 11$ ) modes for specimen plates A1H and A1D (first 8 modes in the 0 to $400 \mathrm{~Hz}$ frequency range).

All these preliminary results show the correctness of the previously stipulated assumptions. One of the postulates confirmed is that it is reasonable to assume that damage is likely to locally reduce the stiffness of the component (and thus a shift on the natural frequencies may 
happen) (figure 8). Furthermore, when a delamination is present, changes in damping caused by interlaminar friction are even more evident (figure 7). Another assumption, that changes introduced by damage into the mode shapes (hence, the PSFs) may be considered negligible, was corroborated as well (figure 8).

\subsection{Damage localisation}

A total of 18 mode shapes was used in this study, obtained during experimental testing in the 0 to $400 \mathrm{~Hz}$ and 0 to $800 \mathrm{~Hz}$ frequency ranges. Damage regions considered were A1, A2, A5 and their symmetric regions $\mathrm{A}^{\prime}$ and $\mathrm{A5}^{\prime}$. In some of the cases, damage suffered an increase by means of quasi-static loading. The damage locations were already shown in figure 4.

The probability for the location of damage is shown by the index values along the plate. Areas with a larger index value are more likely to be damage locations. A summary of the results are presented in figure 9 where it can be seen that, generally, the index assumes larger values close to the true damage region, although some misses also happened.

However, figure 9 does not show results for the case in which $\mathrm{A} 1 \mathrm{H}$ is involved. This is due to the fact that case $\mathrm{A} 1 \mathrm{H}$ was only measured in the 0 to $400 \mathrm{~Hz}$ frequency range. Thus, the index was tested using what it shall be called as the lower order modes, corresponding to the 0 to $400 \mathrm{~Hz}$ frequency range with 8 modes only. Results for all cases are presented in figure 10.

Observation of figure 10 shows that not only the amount of available modes is important, but also the lower order modes are necessary in damage locating techniques. In fact, while using the same set of modes, most of the results are not very different from each other when comparing different damage cases - H-D, D-DD and H-DD - for the same location. This raises the question of what is the contribution of higher order modes in the results. To answer this question, the index was again plotted in figure 11, but this time in the 400 to $800 \mathrm{~Hz}$ frequency range.

It seems that, when used separately, higher order modes tend to provide several falsepositives worsening the damage prediction than when lower order modes are used alone. Nevertheless, it should be stressed out that there is not enough data at this stage to definitely formulate such a conclusion, as no deeper analysis was made in order to understand how the choice of modes affect the results or to determine the optimal amount of modes to be used. As pointed out further ahead, another study would be required to assess the possibility of obtaining such a combination of modes (for a given specimen) that would allow for a uniform (or as close as possible to it) sensitivity across the entire specimen. 
In the illustrated experimental examples, the remark that the use of as many modes as possible is desirable is not at all evident.

However, the observation that some modes may be equally sensitive to different damage locations, possibly due to modal shape symmetry, is pointed out. For instance, when considering the lower part of the frequency range ( 0 to $400 \mathrm{~Hz}$ with modes 1 to 8 only), cases $A 2 \mathrm{H}-\mathrm{A} 2 \mathrm{D}, \mathrm{A} 2 \mathrm{H}-\mathrm{A} 2 \mathrm{DD}, \mathrm{A} 2^{\prime} \mathrm{H}-\mathrm{A} 2^{\prime} \mathrm{D}$ and $\mathrm{A} 2^{\prime} \mathrm{H}-\mathrm{A} 2^{\prime} \mathrm{DD}$ are conducting to the prediction of the same damage location (A2), which is true for the first two cases but false for the other two.

Another observation that rises is how is the damage severity affecting the results: In spite of the fact that the damage was not quantified, it is clear that - as expected - the middle column on the previous figures is the one where best predictions were obtained as it corresponds to the most discrepant situation available between two states of the structure (H-DD). 


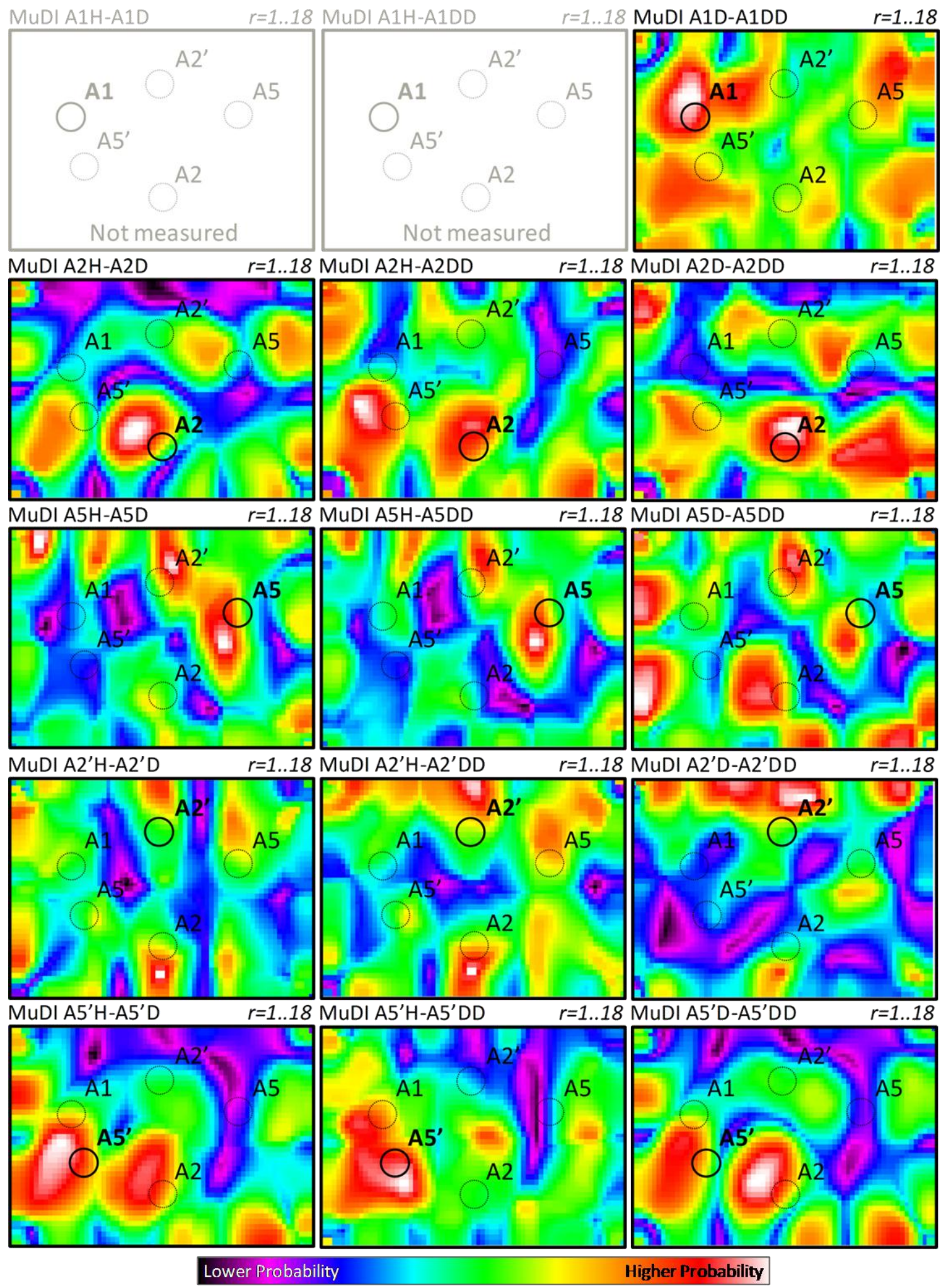

Fig. 9: Experimental location results for specimen plate type ' $A$ '. 


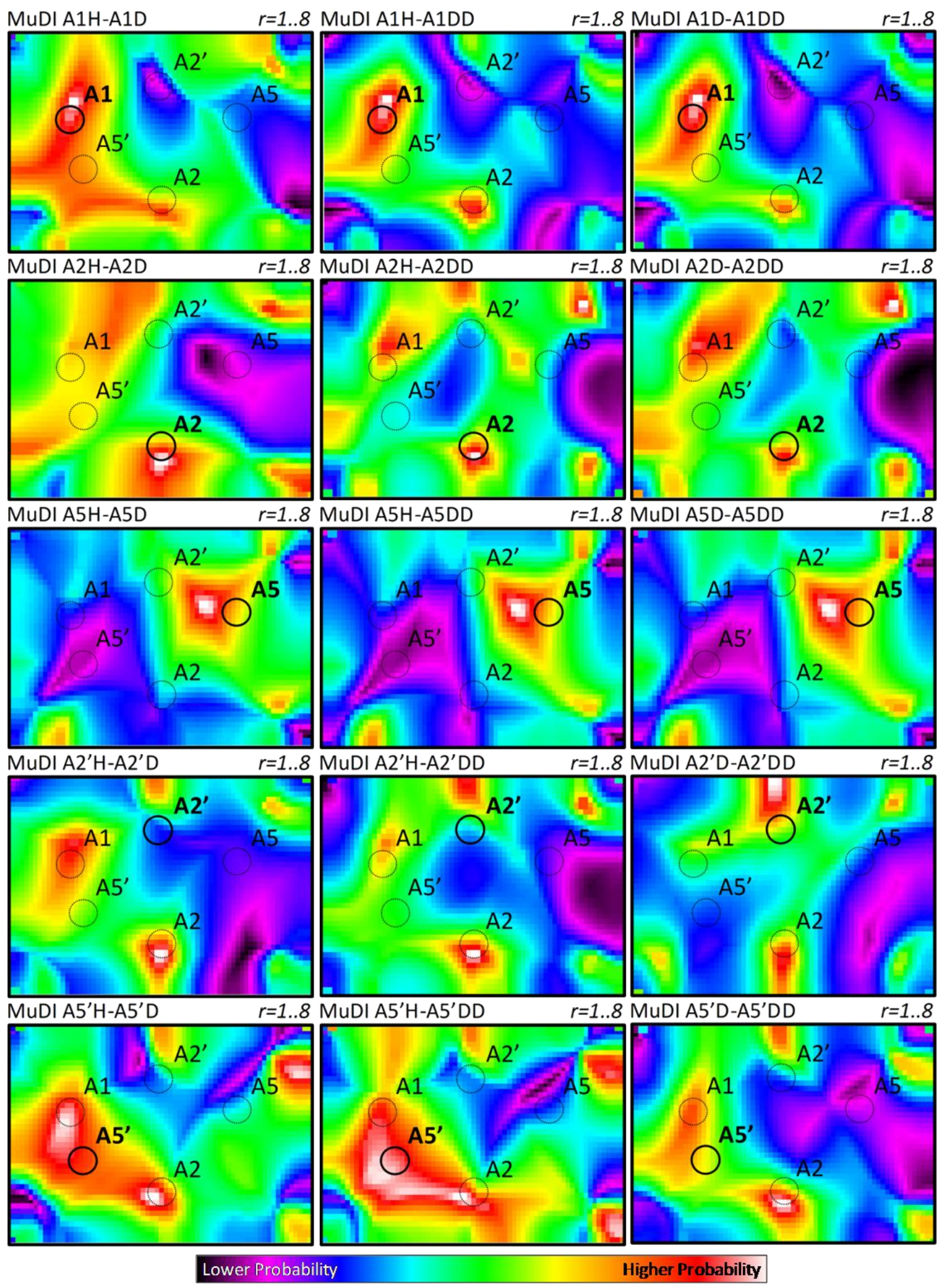

Fig. 10: Experimental location results for specimen plate type ' $A$ ' - lower order modes. 


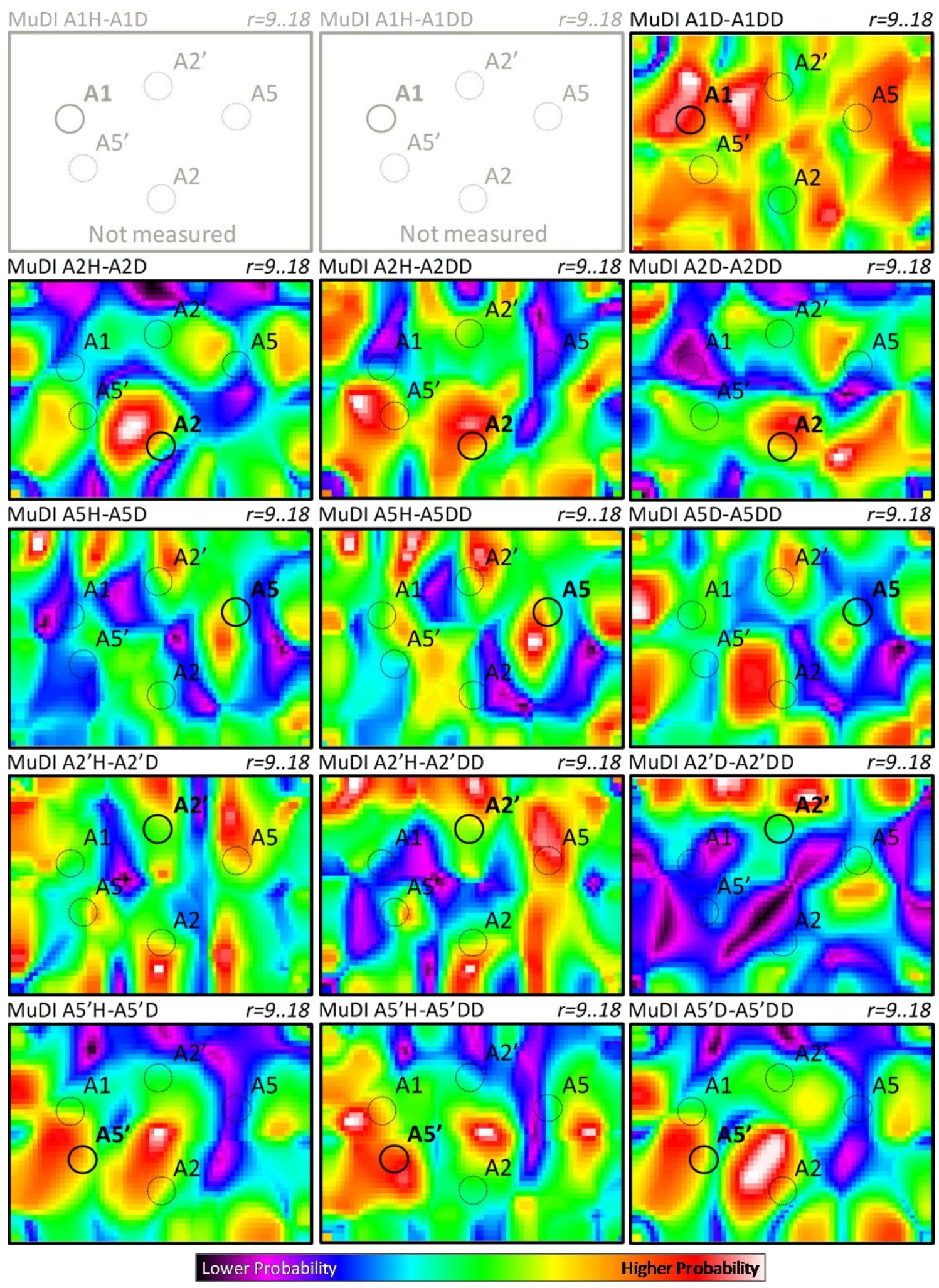

Fig. 11: Experimental location results for specimen plate type ' $A$ ' - higher order modes.

A very simple exercise was performed, that also helped to gain deeper insight about the effects of the amount and combination of modes used in the damage locating index. Every 
single element of figures 9 to 11 was qualified regarding the damage location was correctly identified or not. The following scoring was given:

- $\quad \mathrm{S}$ - Success (only the true location is identified);

- D - Doubt (the true location and some more are likely to be damage locations);

- F - Failure (missed the true location).

The results are shown in table 1. The most unsuccessful results were obtained when using the higher order modes (modes 9 to 18 in the 400 to $800 \mathrm{~Hz}$ frequency range) with a percentage of success of $8 \%$ only and a percentage of failure of $38 \%$, mainly due to the excessive amount of false-positives. On the other hand, the most successful results were obtained when using the lower order modes (modes 1 to 8 in the 0 to $400 \mathrm{~Hz}$ frequency range) with a percentage of success of $60 \%$ and a percentage of failure of $27 \%$. Using all the modes (modes 1 to 18 in the 0 to 800 frequency range) the percentage of success got smaller, $38 \%$, and the percentage of failure decreased slightly (23\%). Nevertheless, if all the 41 results are bundled together, only 12 were a failure, which correspond to only $29 \%$ of the overall results. From the maintenance point of view, since false-positives are not nearly as much of a problem as false-negatives, using all modes would be the best option, since it has the lowest failure rate.

Table 1: Scoring table of the experimental results.

\begin{tabular}{cccccccccc}
\hline Damage & \multicolumn{3}{c}{ All modes (1-18) } & \multicolumn{3}{c}{ Lower order modes (1-8) } & \multicolumn{3}{c}{ Higer order modes (9-18) } \\
Case & H-D & H-DD & D-DD & H-D & H-DD & D-DD & H-D & H-DD & D-DD \\
\hline A1 & n.a. & n.a. & S & S & S & S & n.a. & n.a. & D \\
A2 & S & D & S & S & S & F & S & D & D \\
A5 & D & S & F & S & S & S & F & D & F \\
A2 $^{\prime}$ & F & D & D & F & F & S & F & D & D \\
A5 $^{\prime}$ & D & S & F & D & D & F & F & D & F \\
\hline Success & $38 \%$ & & & $60 \%$ & & & $8 \%$ & \\
Doubt & $38 \%$ & & & $13 \%$ & & & $54 \%$ & \\
\hline Failure & $23 \%$ & & & $27 \%$ & & & $38 \%$ & \\
\hline
\end{tabular}

\subsection{The weighting coefficients and damage}

The previous results do not show how the damping and frequency weighting coefficients, $W_{d}$ and $W_{f}$ respectively, are influencing (or being influenced by) the results. These coefficients translate the relative influence of the DaDI and FreDI on the MuDI as a measure of their 
relative relevance. Figures 13 to 14 exemplify how each of these indexes performs and how the FreDI and DaDI contribute to the damage location prediction from MuDI (these pictures are illustrative of the observed cases).

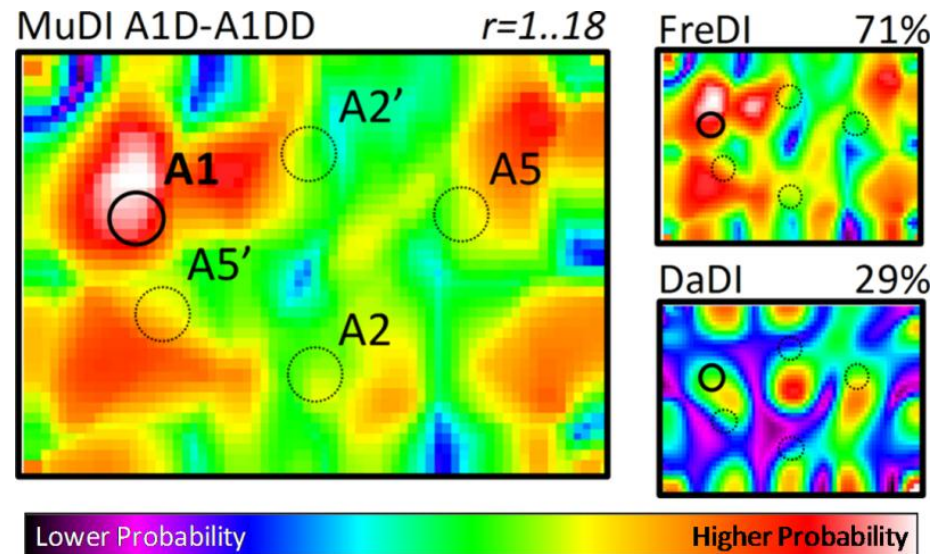

Fig. 12: Experimental location results (MuDI, FreDI and DaDI) and weighting coefficients for damage case A1D-A1DD in the whole measured frequency range (0 to $800 \mathrm{~Hz}$, modes 1 to 18 ).

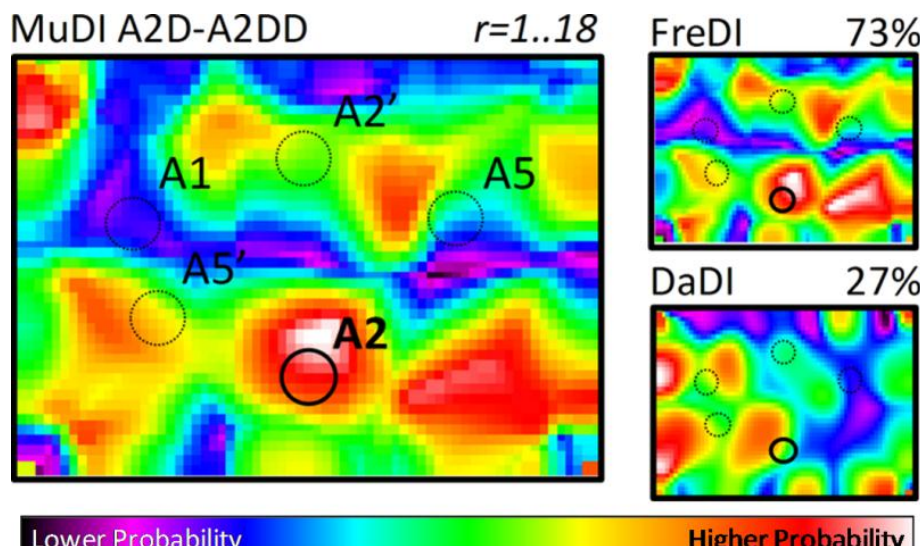

Fig. 13: Experimental location results (MuDI, FreDI and DaDI) and weighting coefficients for damage case A2D-A2DD in the whole measured frequency range (0 to $800 \mathrm{~Hz}$, modes 1 to 18).
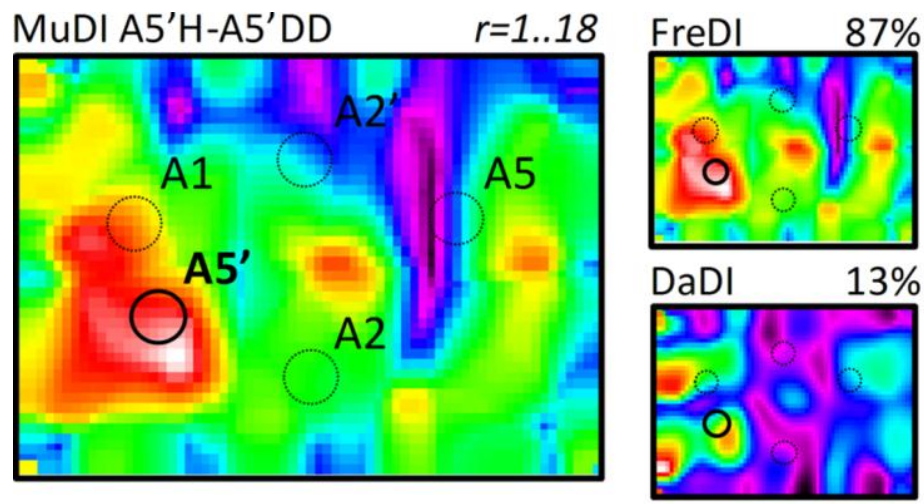
Fig. 14: Experimental location results (MuDI, FreDI and DaDI) and weighting coefficients for damage case $A 5^{\prime} \mathrm{H}-\mathrm{A} 5^{\prime} \mathrm{DD}$ in the whole measured frequency range $(0$ to $800 \mathrm{~Hz}$, modes 1 to 18).

As can be seen in these examples, the values of the weighting coefficients generally are a good measure of the relative quality of each index, as expected. Accordingly, a study about the performance of each index can be performed using the weighting coefficients. As an example, the values of the weighting coefficient $W_{d}$ of the results for the lower order modes previously presented are plotted in figure 15 with respect to each damage case.

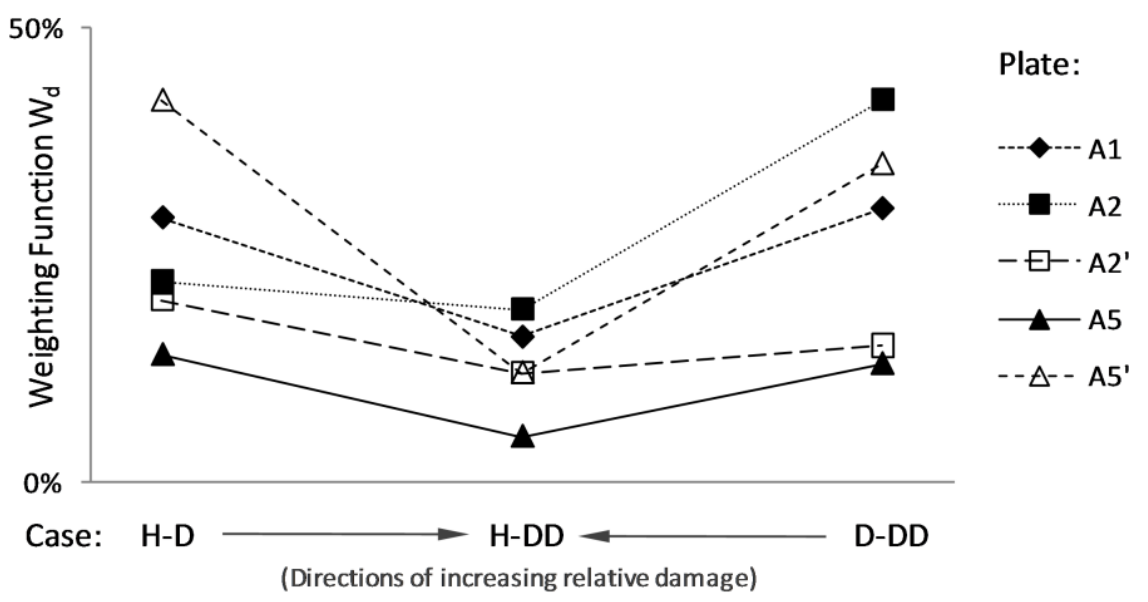

Fig. 15: Experimental weighting coefficients $W_{d}$-evolution with relative damage (from H-D to $H-D D$ and from D-DD to H-DD).

Figure 15 provides a hint on the usefulness of the weighting coefficients, not only in the damage location identification, but also on the quantification of damage and, possibly, even on the qualification of damage. The growth of damage noticeably leads to smaller values of the damping weighting coefficient or, in other words, to larger values of the frequency weighting coefficient. Fifteen states of the structure allowed establishing ten damage scenarios, and the previous observation is valid in all cases, showing coherence and consistency on the results. Damping has a more important influence on the index when the relative damage is smaller, which is to say that frequency has a more important influence on the index when the relative damage is larger. What might be happening is that, by increasing damage, fibres are breaking instead, having a more prominent effect on the frequency change than increasing the delamination region does on the damping factor change. This, of course, needs further study 
and development in the sense that the micromechanics of the fracture should be detailed thoroughly to allow for further conclusions and eventual generalisation.

Nevertheless, it is notorious that the damping weighting coefficients $W_{d}$ are much smaller than the frequency weighting coefficients $W_{f}$. In fact, $W_{d}$ oscillated between $5 \%$ and $42 \%$; as a consequence, MuDI is mostly governed by FreDI instead of DaDI, at least for the experimental cases presented and the way the weighing metrics were defined. Observation of figures 13 to 14 also shows that MuDI is not that different from FreDI. Still, it shows that DaDI, despite not providing good damage location predictions in any case, is giving a favourable contribution by slightly fading eventual false-positives that would be very marked if FreDI was used alone.

In other words, the location of damage was mostly dominated by frequency shifts (or stiffness changes), especially when the relative damage was larger. This is of course a consequence of the way the weighting coefficients are determined and adjustments could be made, as these are based on an empiric metric. The point is that the location of damage was, to a certain extent, accurately made with a strong contribution from the frequency shifts. This is, of course, consistent with the above remarks about the matter.

\subsection{Frequency and damping variations with damage level}

Table 2: Maximum values of the experimental relative differences of the damping factors and natural frequencies.

\begin{tabular}{ccccccc}
\hline Damage & \multicolumn{3}{c}{ Natural Frequencies } & \multicolumn{3}{c}{ Damping Factors } \\
Case & H-D & H-DD & D-DD & H-D & H-DD & D-DD \\
\hline A1 & $0.55 \%$ & $1.81 \%$ & $1.27 \%$ & $51.0 \%$ & $77.2 \%$ & $163 \%$ \\
A2 & $0.72 \%$ & $0.70 \%$ & $0.53 \%$ & $31.6 \%$ & $54.5 \%$ & $67.1 \%$ \\
A5 & $0.91 \%$ & $1.79 \%$ & $0.88 \%$ & $40.1 \%$ & $59.0 \%$ & $157 \%$ \\
A2' $^{\prime}$ & $0.58 \%$ & $1.12 \%$ & $0.74 \%$ & $23.4 \%$ & $42.7 \%$ & $34.7 \%$ \\
A5' & $1.31 \%$ & $2.05 \%$ & $1.18 \%$ & $131 \%$ & $40.3 \%$ & $50.6 \%$ \\
\hline Average & & $1.08 \%$ & & & $68.3 \%$ & \\
\hline
\end{tabular}

It would be interesting to observe how the natural frequencies and the damping factors changed with the damage level (table 2). Overall, the first thing to be pointed out is that, on average, the largest natural frequency variation is roughly 50 times smaller than the damping factor variation, for the given experimental examples. 
These results reinforce the conclusions from the previous section, namely that, at least in the given experimental examples, the damage location identification algorithm includes a strong contribution from frequency shifts, even if they are much smaller than the damping changes.

\section{Conclusions}

A method for locating damage in composite materials was presented and tested. Conventional, "low-cost" and generally easy to obtain equipment was used. This method is based on the modal damping factors and natural frequencies variations from a reference state to a damaged state. It also makes use of the modal shapes, described by what is called a Plane Shape Function (PSF), as a tool that spatially describes the local sensitivity to damage. The damage location is assessed by an index that provides a geometrical distribution of a measure of the probability (in the sense of likelihood) of damage.

It is possible to highlight the following advantages of this method:

- In principle, only one response transducer is needed (more may be required to avoid modal nodes and to reduce the uncertainty);

- It is applicable at low-cost to structures that have not been previously instrumented;

- It is sensitive to damping and stiffness dependent damage.

As disadvantages, the following can be pointed out:

- It is strongly dependent on the quality of (FEM or measured) mode shapes description;

- It is neither false-positive nor false-negative free, although false-positives seem more likely to occur;

- It requires a dynamic reference condition state of the structure.

Other comments to note are the following:

- It was confirmed that the frequency shifts are considerably smaller than the damping shifts that can get considerably larger when damage is present in CFRPs;

- The previous point does not invalidate that the frequency cannot be a good candidate to be used as feature for locating damage; it was experimentally shown that the 
uncertainty involved when measuring the modal frequency is small enough to allow it to be used as damage feature even for very slight variations ${ }^{8}$;

- The uncertainty involved while measuring the modal damping factor may still be a hindrance for its use in damage locating techniques;

- Both the previous points could be reasons behind the worse performance of DaDI when compared to FreDI;

- It is the belief of the authors that, experimental uncertainties aside, the choice between damping and frequency as features for locating damage is mainly dependent upon the type of existing damage;

- Results show that the use of a greater amount of mode shapes to compute the damage index not always leads to better results;

- The modal sensitivity differences from a damage location to another are used in the method but also imply differences in its performance for different damage locations.

Further research is still required, however, in order to improve the sensitivity of the method and avoid both false-positives and mainly false-negatives. It is the belief of the authors that further developments of this technique will allow both to provide a measure of the severity of damage and to distinguish between delamination and fibre breakage in CFRPs. Besides, the method was tested for rectangular plates so far and is expected to perform similarly for any other bi-dimensional structure.

\section{Acknowledgements}

The authors gratefully acknowledge Prof. Patrick Guillaume and his Ph.D. student (now Dr.) Ing. Christof Devriendt from the Faculty of Applied Sciences of the Vrije Universiteit Brussel for the use of their laboratory equipment in their facilities, in particular two scanning LASER vibrometers, as well as giving valuable advices and guidance in the experimental testing.

Thanks are also due to Prof. João Travassos and Ing. Paulo Caldeira from Instituto Superior de Engenharia de Lisboa of the Polytechnic Institute of Lisbon for the use of their autoclave and consumables for the production of CFRP plates, as well as to Prof. Rui de Carvalho from Instituto Superior Técnico of the Technical University of Lisbon and Ing. Marco Leite from

\footnotetext{
${ }^{8}$ The environmental conditions were the same when measuring different damaged states, not introducing disturbing effects on the results.
} 
Escola Superior de Tecnologia de Abrantes of the Polytechnic Institute of Tomar for the help and expertise on the introduction of damage in the CFRP laminates.

The authors would like to acknowledge Fundação para a Ciência e a Tecnologia (FCT) and the European Social Fund under the frame of III Community Support Framework, for financial support through grant reference number SFRH / BD / 27329 / 2006.

\section{References}

[1] F. L. Matthews, Damage in Fibre Reinforced Plastics; Its Nature, Consequences and Detection, Proceedings of the $3^{\text {rd }}$ International Conference on Damage Assessment of Structures (DAMAS 99), Dublin, Ireland, 1999, pp. 1-16.

[2] A. J. P. F. Silva, Propagação de Delaminagem em Compósitos de Matriz Polimérica, PhD Thesis, Instituto Superior Técnico, Technical University of Lisbon, Portugal (in Portuguese), 2001.

[3] R. J. S. Carvalho, Resistência Residual de um Compósito de Matriz Epóxídica reforçado por Fibras de Carbono após Reparação, PhD Thesis, Instituto Superior Técnico, Technical University of Lisbon, Portugal (in Portuguese), 2003.

[4] S. Abrate, Impact on Composite Structures, Cambridge University Press, 1998.

[5] W. A. Morais, S. N. Monteiro, J. R. M. d'Almeida, Effect of the Laminate Thickness on the Composite Strength to Repeated Low Energy Impacts, Composite Structures, 70 (2005) pp. 223-228.

[6] S. D. Bartus, A Review: Impact Damage of Composite Materials, Journal of Advanced Materials, 39(3) (2007) pp. 3-21.

[7] A. Zak, M. Krawczuk, W. Ostachowicz, Vibration of a Laminated Composite Plate with Closing Delamination, Proceedings of the $3^{\text {rd }}$ International Conference on Damage Assessment of Structures (DAMAS 99), Dublin, Ireland, 1999, pp. 17-26.

[8] L. H. Yam, Z. Wei, L. Cheng, Nondestructive Detection of Internal Delamination by Vibration-based Method for Composite Plates, Journal of Composite Materials, 38(24) (2004) pp. 2183-2198.

[9] Y. Zou, L. Tong, G. P. Steven, Vibration-Based Model-Dependent Damage (Delamination) Identification and Health Monitoring for Composite Structures - A Review, Journal of Sound and Vibration, 230(2) (2000) pp. 357-378.

[10] P. Cawley, R. D. Adams, The Location of Defects in Structures from Measurements of Natural Frequencies, Journal of Strain Analysis for Engineering Design, 14(2) (1979) pp. 49-57.

[11] S. Keye, M. Rose, D. Sachau, Localizing Delamination Damages in Aircraft Panels from Modal Damping Parameters, Proceedings of the $19^{\text {th }}$ International Modal Analysis Conference (IMAC XIX), Kissimmee, Florida, USA, 2001, pp. 412-417.

[12] C. Kyriazoglou, B. H. Le Page, F. J. Guild, Vibration Damping for Crack Detection in Composite Laminates, Composites, Part A: Applied Sciences and Manufacturing, 35 (2004) pp. 945-953.

[13] D. Montalvão, A. M. R. Ribeiro, J. Duarte-Silva, A Method for the Localization of Damage in a CFRP Plate using Damping, Special Issue on Inverse Problems in Mechanical Systems and Signal Processing, 23 (2009) pp. 1846-1854.

[14] D. Montalvão, A Modal-based Contribution to Damage Location in Laminated Composite Plates, PhD Thesis, Instituto Superior Técnico, Technical University of Lisbon, Portugal, 2010. 
[15] D. Montalvão, A. M. R. Ribeiro, N. M. M. Maia, J. Duarte-Silva, R. A. Cláudio, Damping Measurements on a Carbon Fibre Reinforced Laminate, Proceedings of the International Conference on Noise and Vibration Engineering (ISMA 2006), Leuven, Belgium, 2006b, pp. 447459.

[16] S. R. Ibrahim, A. A. Seafan, Correlation of Analysis and Test in Modelling of Structures and Review, Proceedings of the $5^{\text {th }}$ International Modal Analysis Conference (IMAC V), London, England, UK, 1987, pp. 1651-1660.

[17] M. I. Friswell, J. E. Mottershead, Finite Element Updating in Structural Dynamics, Kluwer Academic Publishers, 1995.

[18] N. M. M. Maia, J. M. M. Silva, A. M. R. Ribeiro, A New Concept in Modal Analysis: The Characteristic Response Function, The International Journal of Analytical and Experimental Modal Analysis, 9(3) (1994) pp. 191-202.

[19] A. M. R. Ribeiro, Desenvolvimento de Técnicas de Análise Dinâmica Aplicáveis à Modificação Estrutural, PhD Thesis, Instituto Superior Técnico, Technical University of Lisbon, Portugal (in Portuguese), 1999.

[20] N. F. Rilo, L. M. S. Ferreira, R. A. C. P. Leal, Low-Velocity Impact Analysis of Glass/Epoxy Plates, Proceedings of the 5th International Conference on Mechanics and Materials in Design (M2D'2006), Porto, Portugal, 2006, ref. A0110.0092. 